\title{
Neurobiological and Psychosocial Risks and Protective Factors of Psychiatric Patients
}

\author{
Sahiti Ganduri \\ PSG College of Arts and Sciences \\ sahitiramesh9@gmail.com
}

\begin{abstract}
Psychopathy is defined and understood as a personality disorder, classified as Antisocial Personality Disorder F60.2 by the International Classification of Disorders 10. The word 'psychopath' however, is making comebacks into modern culture, to define set standards about low-empathetic behaviour. Cultivation of various studies, infer that the part of the brain responsible for feelings of empathy fails to respond, when psychopaths see other people in pain (Decety J, Chen C, Harenski C and Kiehl KA (2013) . Recent studies show numerous new findings in the behaviour and neurological (functional and structural) features of psychopaths. Psychopathy is a symptom complex consisting of affective (emotional) deficits, interpersonal (interpersonal skills) deficits, and impulsive behaviors such as aggression, substance abuse, and chronic lying. This study aims to provide a detailed analysis of various researched findings of psychopathic behaviour. The findings from this study aims to provide a validated scope of understanding for future development in the field of antisocial personality disorder
\end{abstract}

Keywords: Psychopathy, Empathy, Aggression, Neurology

\section{Psychopathy: A Brief Study of the Past Understandings-An Introduction}

Psychopathy is a form of antisocial personality disorder, persistent with impaired empathy, social skills, egotistical traits, lack of regret and remorse. Psychopaths are synonymous with sociopaths and narcissists. However, there are many studies that are characterizing the importance of providing a differential understanding of psychopaths and sociopaths. Pemment, J. (2013) This study expresses the absolute need for providing a distinction. The author claims that, while psychopaths exhibit no remorse or guilt, sociopaths are indicative of expressing social conjecture, having a moral conscience. International Classification of Disorders classifies antisocial personality disorder with psychopathic personality under F60.2. The clinical information provided states that it is "A disorder characterized by a pervasive pattern of disregard for and violation of the rights of others that is manifested in childhood or early adolescence." Psychopaths are often determined to show little to no remorse toward the illfeelings of other people. It is also defined as a personality disorder characterized by conflict with others, low frustration tolerance, inadequate conscience development, and rejection of authority and discipline.

Neuroscientist James Fallon discussed and provided outstanding findings on the path of understanding the psyche of a psychopath. Some of the key findings involved lower functioning in the amygdala, which controls impulsivity (Moul, Killcross \& Dadds, 2012) as well as low functioning in the prefrontal cortex, which is responsible for the control of sense and morality in a person.(Kiehl et al, 2011). Naturally, lower activity in both areas would result in the induction of a psychopath- with low impulse control and thus behaving recklessly, dangerously and also with a strong sense of morality, thus exhibiting no remorse or regret. Different scientists have different opinions about psychopathic behaviour. While some believe that environmental factors are at play, others are of the strong notion that genetics and epigenetic factors inhibit psychopathic behaviour. For a very long time, environmental theorists Daversa, M. T. (2010). Had the upper hand in understanding psychopathic behaviour, however lately, genetic modules seem to provide a better understanding of psychopaths. Nonetheless, it is important to note that both variants have an equal role at explaining the behaviour of psychopaths Fallon HJ, 2006. The extent of this article, aims to provide an understanding of psychosocial and neurobiological factors of psychopaths, through an extensive course of developmental and clinical literature across topic areas.

\section{Understanding Neurobiology of Psychopathy}

Each year, $2.2 \%$ of prisoners are diagnosed with psychopathy. Though it has been labelled as a subtype, it is more of the result of deficits in neurological functioning. fMRI case studies Hoff, H., Beneventi, H., Galta, K., \& Wik, G. (2009). provide evidence that the processing of emotional stimuli in a psychopath is atypical. The structural and functional aspects of the brain in a psychopath seem to play a major role in their behaviour. One study showed that psychopaths have reduced connections between the ventromedial prefrontal cortex (vmPFC) which regulates empathy and guilt, and the amygdala which is responsible for emotions of fear and anxiety. Blair, R. J. R. (2007). 


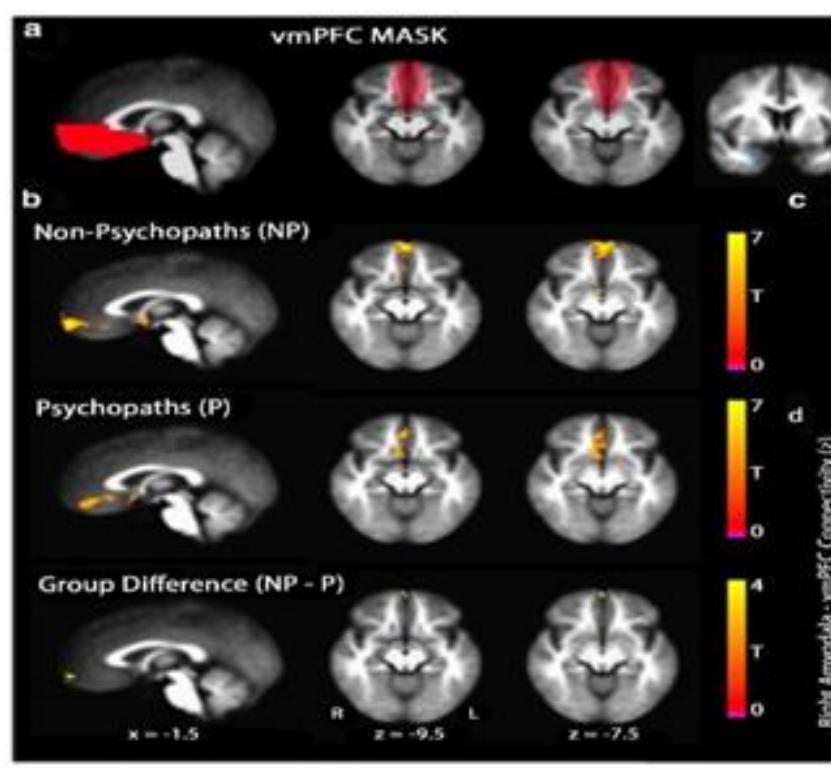

Figure 1: Functional connectivity between amygdala and vmPFC is reduced. The group difference map shows an area where non-psychopaths have greater connectivity than psychopaths. a, shows group differences assessed in connectivity of vmPFC for correlated coefficients computed using mean time series extracted from hand drawn right amygdala. $b$, shows the mean right amygdala- vmPFC connectivity in non-psychopaths and psychopaths, as well as a separate group difference. c, shows a 3-dimensional structure of the brain to identify locations of amygdala and PFC. d, computes a bar plot to depict the significant group difference in connectivity estimates (Fisher $z$-transformed correlation coefficients) within the vmPFC cluster. Error bars indicate SEM. Filled circles represent values from individual subjects.

The amygdala is involved in aversive conditioning and instrumental learning (LeDoux, 1998). As mentioned above we have understood the nature of the relationship of Amygdala and vmPFC, that results in psychopathic behaviour. Other researchers, (Tiihonen et al , 2000; Kiehl et al , 2001) tried to identify other parts and functions of the brain to understand psychopathic behaviour. Tiihonen et al, 2000 conducted Magnetic Resonance Imaging on 18 male, violent offenders, charged with offences ranging from homicide, attempted homicide, assisting homicide, armed robbery, assault. The results showed significant negative correlation with the posterior half of the hippocampus and the degree of psychopathy. Kiehl, 2006 provided studies that lead to evidence that damage to the orbital frontal cortex appears to be associated with cognitive impairments that can be found in psychopaths.

Psychopaths have difficulty attributing guilt to characters in stories Blair et al, 1995, they have difficulty understanding emotional metaphors and do not make appropriate use of emotional content in language Herve et al, 2003. During other studies, evidence has been found that the processing of abstract words while performing lexical decision tasks, the right anterior superior temporal gyrus fails to activate, stipulating that this brain region (responsible for processing concrete words) is functionally impaired in psychopaths. Kiehl et al, 2004. These depict the abnormalities and impairments of semantic processing in psychopaths.
Damage to the prefrontal cortex can give rise to psychopathic behaviour (Damasio, 1994). However, individual differences in psychopathy correlate with reduction of gray matter in the prefrontal cortex. An fMRI study (Raine \& Yang, 2005) showed that unsuccessful psychopaths have reduced volume in their prefrontal gray matter. Another fMRI study, (Raine et al, 2003) provided evidence of increased volume of the corpus callosum in psychopaths.

Increased volume of the corpus callosum significantly results in blunted affect, lack of social closeness, lack of remorse, and no close friends. It also implies reduced heart rate activity during exposure to stressor, which can perhaps explain the failure of aversive conditioning in psychopaths (Flor et al, 2002).

The above research explains how the functional and structural dysfunctions of different parts of the brain can result in psychopathic behaviour. This review also explains the psychosocial implications of psychopathic behaviour.

\section{Psychosocial Implications of Psychopathy}

Empathy is defined as the capacity to 'share' and understand another's "state of mind" or emotion. (Ioannidou \& Konstantikaki, 2008).

In general, psychopaths are antisocial and violent, for reasons that non-psychopaths cannot comprehend. Psychopaths, (Hare, Babiak \& McLaren, 2007) are egocentric, without conscience and incapable of deep human emotions; love and compassion in particular. Psychopaths tend to gaslight their victim, they even blame the victim for the (victim's) sufferings, and victims fall prey and doubt their own residue.

Psychopaths can hide their true intentions, and act likeable to the victims before committing the crime. (Hare, Babiak \& McLaren, 2007). The lack of empathy in psychopaths has triggered many questions. The low fear theory, with studies supporting impaired aversive conditioning (Blair et al, 1997) can hypothesize to some extent that the individual does not have any fear for the negative consequences of his actions. Further, psychopaths have severe difficulty in making decisions on the basis of both reward and punishment. (Blair, Morton et al, 2006). However, alternative theories suggest that the general inability of a psychopath to detect or read facial expressions and act under social cognition can be a cause for the lack of empathy, as they cannot comprehend the pain in the other person through facial readings. (Blair, 2005).

Empathy in itself, can be defined through "Theory of mind" (Cognitive empathy), Motor empathy and the perception action-model and emotional empathy. Out of this, studies have shown that psychopaths have no difficulty processing Theory of mind and to an extent even, motor empathy. They do show marked difficulties pertaining to emotional empathy. (Blair, 2005). They have a hard time expressing and comprehending emotions of fear, sadness and disgust. This impairment in particular, can be a possibility of their amygdala dysfunction. Emotional dysregulation has placed 
substantial emphasis that it not only causes difficulty in refraining from impulsive behaviours, but also leads to limited awareness, acceptance and understanding of emotion. (Neuman, Garofalo et al, 2020). This perspective can help us understand that limited awareness and understanding of their own emotions, can make such individuals cold, enraged and thus, resulting in aggressive behaviour (to a certain extent).

Psychopaths share narcissistic personality traits. They have a high self-esteem, are extremely egoistic and believe themselves to be above all. They are considered "malignant narcissists." (Shafti, 2019). Thus, in order to protect this 'image' and avoid a downfall in their self-concept, psychopaths can engage in aggressive and violent behaviour. (Baumeister, Smart \& Boden, 1996). Psychopaths are more likely to respond to ego-threats in the form of aggression than non-psychopaths. Studies also showed that the association between psychopaths and aggression, in light of ego threat, was showcased more in the form of verbal aggression, as compared to physical aggression.(Cale \& Lilienfeld, 2006).

Another explanation of aggressive behaviour in psychopaths, can be taken from the understanding of reduced gray matter volume in the brain, particularly superior frontal gyrus. An MRI study (Hofhansel, Weidler, Votinov, et al, 2020) showed a distinct inverse correlation between gray matter volume and psychopathy. Higher the PCL-R (Psychopathy Checklist- Revised- Hare, 2003), lesser gray matter volume was found in the Superior prefrontal cortex. We know that the prefrontal cortex is responsible for emotions of empathy and guilt, and studies (Koenigs, Hauser, Damasio, Young et al, 2007) also show that damage to the vmPFC also causes decrease in moral judgement, which can further explain the lack of remorse in psychopaths who engage in aggressive behaviour and express no guilt after the act.

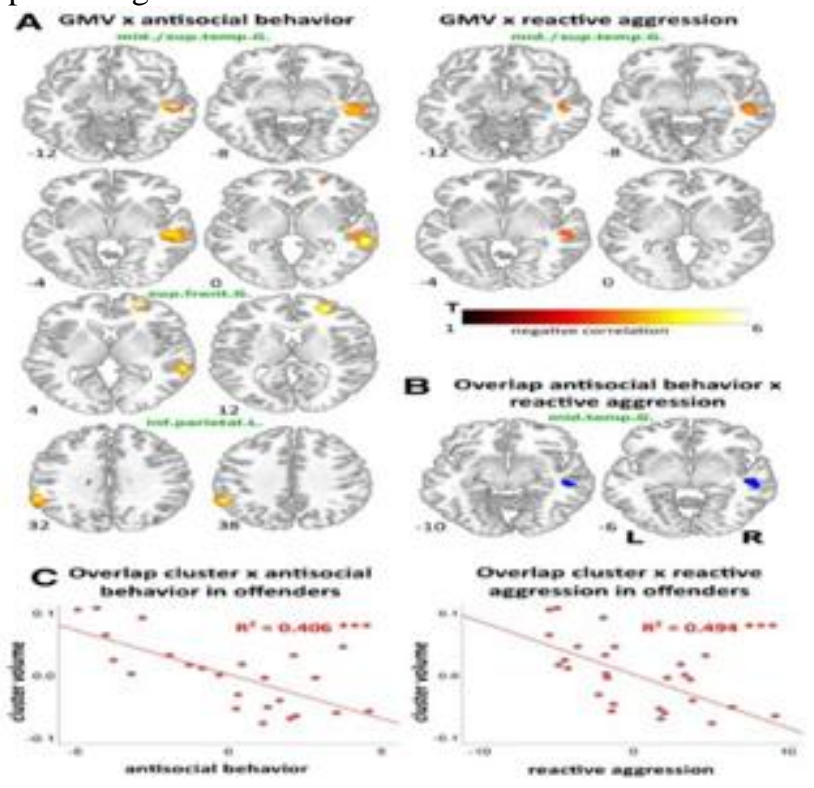

Figure 2: Overlapping cluster and correlational study between aggressive behavior and reduced volume/ morphology of gray matter in the brain. Results depict lesser gray matter in superior frontal gyrus with increasing psychopathy.
The above depicted figure explains the inverse correlation between global psychopathy and low gray matter volume.

\section{Limitations}

This study has to be seen in the light of some limitations. There is, but a brief understanding of the different factors involved to depict neurobiological and psychosocial aspects of psychopathy. To define a psychopath would involve far deeper convictions and factorial representations. The study also dwells into a single understanding of antisocial personality disorder, and does not involve the presentations of other subtypes. The understanding of antisocial personality disorder is a little more complex than the other disorders in Cluster B (Personality disorders- DSM V).

Further research can improve the understanding of personality disorders, particularly antisocial personality disorder. There is a high scope for discussion in this particular area of study. Further, being a review article and the lack of empirical study, constraints the author's primary experience with research.

\section{Conclusion}

This particular review article has been an integrated study of different research papers in the field of Psychopathy, particularly the neurobiological and psychosocial aspects of psychopathy. It has been understood that different parts of the brain and their functions (or dysfunctions, thereof) contribute to psychopathic behaviour; the Amygdala and Ventromedial Prefrontal Cortex in particular, which explains the lack of empathy, fear and guilt in psychopaths.

Aggression is a well-established behaviour in psychopaths. Again, the structure of the brain i.e. the reduced gray matter volume in the prefrontal cortex, has a direct impact on aggression. Apart from that, psychopaths are entrenched narcissists, and their aggressive behaviour can be explained, as a technique to protect their self-esteem. Their indifference toward aversive conditioning, low empathy and guilt, inability to understand social emotions can help understand their aggressive behaviour.

\section{References}

[1] Decety, J., Chen, C., Harenski, C., \& Kiehl, K. A. (2013). An fMRI study of affective perspective taking in individuals with psychopathy: imagining another in pain does not evoke empathy. Frontiers in human neuroscience, 7, 489.

[2] Pemment, J. (2013). Psychopathy versus sociopathy: Why the distinction has become crucial. Aggression and Violent Behavior, 18(5), 458-461. https://www.icd10data.com/ICD10CM/Codes/ F01F99/F60-F69/F60-/F60.2

[3] Moul, C., Killcross, S., \& Dadds, M. R. (2012). A model of differential amygdala activation in psychopathy. Psychological review, 119(4), 789.

[4] Motzkin, J. C., Newman, J. P., Kiehl, K. A., \& Koenigs, M. (2011). Reduced prefrontal connectivity in psychopathy. Journal of Neuroscience, 31(48), 
17348-17357. (Refer Figure 1)

[5] Daversa, M. T. (2010). Early environmental predictors of the affective and interpersonal constructs of psychopathy. International journal of offender therapy and comparative criminology, 54(1), 6-21.

[6] Fallon, J. H. (2017). Neuroanatomical background to understanding the brain of the young psychopath. In Biosocial Theories of Crime (pp. 395-421). Routledge.

[7] Hoff, H., Beneventi, H., Galta, K., \& Wik, G. (2009). Evidence of deviant emotional processing in psychopathy: A fMRI case study. International Journal of Neuroscience, 119(6), 857-878.

[8] Blair, R. J. R. (2008). The amygdala and ventromedial prefrontal cortex: functional contributions and dysfunction in psychopathy. Philosophical Transactions of the Royal Society B: Biological Sciences, 363(1503), 2557-2565.

[9] Blair, R. J. R. (2003). Neurobiological basis of psychopathy. The British Journal of Psychiatry, 182(1), 5-7.

[10] Motzkin, J. C., Newman, J. P., Kiehl, K. A., \& Koenigs, M. (2011). Reduced prefrontal connectivity in psychopathy. Journal of Neuroscience, 31(48), 17348-17357.

[11] Laakso, M. P., Gunning-Dixon, F., Vaurio, O., RepoTiihonen, E., Soininen, H., \& Tiihonen, J. (2002). Prefrontal volumes in habitually violent subjects with antisocial personality disorder and type 2 alcoholism. Psychiatry Research: Neuroimaging, 114(2), 95-102.

[12] Kiehl, K. A. (2006). A cognitive neuroscience perspective on psychopathy: Evidence for paralimbic system dysfunction. Psychiatry research, 142(2-3), 107-128.

[13] Blair, R. J. R., Sellars, C., Strickland, I., Clark, F., Williams, A. O., Smith, M., \& Jones, L. (1995). Emotion attributions in the psychopath. Personality and Individual Differences, 19(4), 431-437.

[14] Hervé, H. F., Hayes, P. J., \& Hare, R. D. (2003). Psychopathy and sensitivity to the emotional polarity of metaphorical statements. Personality and Individual Differences, 35(7), 1497-1507.

[15] Hervé, H., \& Yuille, J. C. (Eds.). (2017). The psychopath: Theory, research, and practice.

[16] Hervé, H. (2017). Psychopathy across the ages: A history of the Hare psychopath. In The psychopath: Theory, research, and practice (pp. 31-55). Routledge.

[17] Hervé, H. F. (2003). The masks of sanity and psychopathy: a cluster analytic investigation of subtypes of criminal psychopathy (Doctoral dissertation, University of British Columbia).

[18] Kiehl, K. A., Smith, A. M., Mendrek, A., Forster, B. B., Hare, R. D., \& Liddle, P. F. (2004). Temporal lobe abnormalities in semantic processing by criminal psychopaths as revealed by functional magnetic resonance imaging. Psychiatry Research: Neuroimaging, 130(1), 27- 42.

[19] Yang, Y., Raine, A., Lencz, T., Bihrle, S., LaCasse, L., \& Colletti, P. (2005). Volume reduction in prefrontal gray matter in unsuccessful criminal psychopaths. Biological psychiatry, 57(10), 1103-1108.

[20] Raine, A., Lencz, T., Taylor, K., Hellige, J. B., Bihrle, S., Lacasse, L., ... \& Colletti, P. (2003). Corpus callosum abnormalities in psychopathic antisocial individuals. Archives of general psychiatry, 60(11), 1134-1142.

[21] Flor, H., Birbaumer, N., Hermann, C., Ziegler, S., \& Patrick, C. J. (2002). Aversive Pavlovian conditioning in psychopaths: Peripheral and central correlates. Psychophysiology, 39(4), 505-518.

[22] Ioannidou, F., \& Konstantikaki, V. (2008). Empathy and emotional intelligence: What is it really about? International Journal of caring sciences, 1(3), 118.

[23] Babiak, P., Hare, R. D., \& McLaren, T. (2007). Snakes in suits: When psychopaths go to work. New York: Harper.

[24] Blair, K. S., Newman, C., Mitchell, D. G., Richell, R. A., Leonard, A., Morton, J., \& Blair, R. J. R. (2006). Differentiating among prefrontal substrates in psychopathy: neuropsychological test findings. Neuropsychology, 20(2), 153.

[25] Blair, R. J. R. (2005). Responding to the emotions of others: Dissociating forms of empathy through the study of typical and psychiatric populations. Consciousness and cognition, 14(4), 698-718.

[26] Garofalo, C., Neumann, C. S., \& Velotti, P. (2020). Psychopathy and aggression: The role of emotion dysregulation. Journal of interpersonal violence, 0886260519900946.

[27] Shafti, S. S. (2019). Malignant Narcissism: Concealed Side of Psychopathy. Biomedical Journal of Scientific \& Technical Research, 22(1), 16310-16315.

[28] Baumeister, R. F., Smart, L., \& Boden, J. M. (1996). Relation of threatened egotism to violence and aggression: the dark side of high self-esteem. Psychological review, 103(1), 5.

[29] Cale, E. M., \& Lilienfeld, S. O. (2006). Psychopathy factors and risk for aggressive behaviour: A test of the "threatened egotism" hypothesis. Law and human behaviour, 30(1), 51-74.

[30] Hofhansel, L., Weidler, C., Votinov, M., Clemens, B., Raine, A., \& Habel, U. (2020). Morphology of the criminal brain: gray matter reductions are linked to antisocial behaviour in offenders. Brain structure and function, 225(7), 2017-2028. (Refer figure 2)

[31] Koenigs, M., Young, L., Adolphs, R., Tranel, D., Cushman, F., Hauser, M., \& Damasio, A. (2007). Damage to the prefrontal cortex increases utilitarian moral judgements. Nature, 446(7138), 908-911. 